\title{
Antimicrobial Efficacy Study Of Acmella Caulirhiza And Spermacoce Princeae Used By Postpartum Mothers In Nyamira County, Kenya
}

\author{
${ }^{1}$ Jespher Nyaboke Onyango ${ }^{* 2}$ Dr. Jackson Odhiambo Onyuka, ${ }^{3}$ Jared Misonge Onyancha ${ }^{* 4}$ Patrick Ogembo \\ Getonto.
}

\author{
${ }^{1}$ Medical Laboratory Department, Mount Kenya University \\ ${ }^{2}$ Medical Laboratory Department, Mount Kenya University \\ ${ }^{3}$ Pharmacognosy Department, Mount Kenya University \\ ${ }^{4}$ Department of Community Health Nursing, Mount Kenya University \\ DOI: 10.29322/IJSRP.11.11.2021.p11967 \\ http://dx.doi.org/10.29322/IJSRP.11.11.2021.p11967
}

\begin{abstract}
Puerperal sepsis is the major cause of (31\%) maternal mortality. Appropriate care could prevent majority of these deaths. Exogenous and endogenous organisms are the causatives agents. Traditional medicine have been used in treating postpartum sepsis for example Acmella caulirhiza used to treat a child's mouth sores and Spermacoce princeae used to accelerate healing of umbilical cord and to clean the system after birth.

The main objective of the present study was to determine antimicrobial activity levels of A. caulirhiza and S. princeae used by postpartum mothers in Nyamira County, Kenya.

The study area was Nyamira County where the two plant specimen and clinical specimens of 339 mothers were collected. Plant materials were identified at East Africa Herbarium. Plant specimens were transported to M.K.U. Pharmacognosy laboratory where processing was done. Clinical specimens were collected from mothers at Nyamira Level 5 Hospital. A single high vaginal swab was collected from each participant, immediately inserted in stuart's transport medium, labeled, placed in a cooler box, triple packaged and transported to Microbiology laboratory of M.K.U. within 48 hours where processing were done. Culture, isolation, identification were done. Disc diffusion method was employed to determine antimicrobial activity in the compounds of the crude plant extracts. Data was stored in Excel spread sheet in a personal computer protected with a password. Antimicrobial activity was analyzed using descriptive statistics. Data was presented using, tables and photographs.

Results: Antibacterial activity of A. caurhiza and S. princeae indicated that, the whole plant extracts had low antibacterial effects against $S$. aureus and E. coli. No antifungal effects were detected for crude extracts of the two plants.

Discussion; the two plants used by the local inhabitants of Nyamira County in treating postpartum infections indicated that, they possess low antibacterial activity against $S$. aureus and $E$. coli. However, no antifungal activity was detected from the two plants.

Recommendation; the two plants may be used in treating postpartum infections though commercially available drugs are recommended as they are highly effective. The two plants indicated low antibacterial activity against $S$. aureus and $E$. coli. However, further studies are recommended on genotoxicity of this plant extracts on $S$. aureus and E. coli genes. Also further research is recommended to isolate and identify pure compounds of the two plants to establish pharmacological basis of antibacterial activity shown even though it was low.
\end{abstract}

Index Terms- Traditional medicine, Disc-diffusion and antimicrobial-activity.

\section{INTRODUCTION}

$\mathrm{T}$ raditional medicine has been used in health maintenance, disease prevention and treatment (WHO, 2014). The use of medicinal plants has been known to mankind as the oldest practice of healthcare (Yogayata and Vijay, 2012). Nowadays, isolation and characterization of biologically active compounds from medicinal plants continues and drug discovery techniques have been applied to the standardization of herbal medicines, to elucidate analytical marker compounds (Marcy and Douglas, 2005). Medicinal plants used to manage postpartum complications include; Basella alba plant which belongs to Asteraceae family, is used to manage stomachache, stimulate milk production and is used to remove the placenta after birth (Jeruto et al., 2015). Toddalia asiatica and Pentas longiflora species which belongs to Rutaceae and Rubiaceae family respectively. The leaves of these herbs are used to manage Urinary tract infections (Jeruto et al., 2015).

Acmella caulirhiza is similarly known as Spilanthes acmella. It is aflowering herbal plant, which belongs to Compositae/Asteraceae family (Berhane et al., 2014). It is an annual or perennial herb. Locally it is known as Ekenyunyuntamonwa (Ekegusii) and Ajuok-olwa Salamatwe (Dholuo) (Kokwaro, 2009). It is used by different communities in Kenya and the rest of Africa to treat various medical conditions. Example in Kenya, its flowers and leaves are used to treat venereal diseases (Jeruto et al., 2015). It 
is used to relief painful sores of the mouth, gums and throat, as well as stomach ache (Kokwaro 2009). Also it is used to treat decayed teeth, gingivitis or wounds in the mouth, toothache and sore throat (Kipruto et al., 2013). The Zulu people of South Africa use A. caulirhiza as a local analgesic for toothache and to ease sensitivity of gums during dental extractions (Crouch et al., 2005).

Spermacoce princeae is flowering herbal plant which belongs to the family Rubiaceae (Augustin et al., 2015). Locally it is known as Omoutakiebo (Ekegusii), Gakungathe (kikuyu), Murkugwet (kipsigis) and Nyamwoch (Dholuo) (Kokwaro, 2009). It grows in tropical regions and it is used are extensively. Normally it is used by different communities in Kenya and the rest of Africa to treat several diseases. Just to mention a few, leaves and roots are used to treat chronic asthma, cancer, mastitis in cows and venereal diseases by the Nandi people in Kenya (Jeruto et al., 2011). Another study carried out in Vihiga County, Kenya found that, cold infusion is made from leaves and drunk in the treatment of diarrhea (Antony et al., 2016). Leaves and stem are used to treat female infertility in Baham, Cameroon (Telefo et al., 2011). In Cameroon, leaves of Spermacoce princeae are warmed on fire, ground and mixed with red oil and salt, then is taken orally in treatment of kidney disease (Focho et al., 2009).

\section{MATERIAL AND METHODS}

\section{Study Area}

The study site was North Mugirango and West Mugirango constituencies of Nyamira County. The study points in West Mugirango constituency were; Sironga $\left(0^{\circ} 33^{\prime} 14.8536 \mathrm{~S}\right.$ and $\left.34^{\circ} 58^{\prime} 2.4996 \mathrm{E}\right)$, Bonyunyu $\left(0^{\circ} 31^{\prime} 36.2532 \mathrm{~S}\right.$ and $\left.34^{\circ} 53^{\prime} 20.4108 \mathrm{E}\right)$ and miruka $\left(0^{\circ}\right.$ $29^{\prime} 13.902 \mathrm{~S}$ and $\left.34^{\circ} 5320.3208 \mathrm{E}\right)$ whereas the study point in North Mugirango constituency was; Magong'a $\left(0^{\circ} 28^{\prime} 46.7724 \mathrm{~S}\right.$ and $34^{\circ}$ 57'6.4836 E) in Nyamira County. In this County, local inhabitants regularly use medicinal plants for personal and domestic animal health. Local inhabitants in this County, follow traditional beliefs and customs. Further, most inhabitants living in this area have a tendency of harvesting the medicinal plants from undisturbed vegetation. This is due to the fact that many plant species grow in the study region (Omwenga et al., 2015). Postnatal mothers use Acmella caulirhiza and Spermacoce princeae to treat child sores and to clean reproductive system respectively in women after birth. Nyamira County is one of highly populated area with approximately 912.5 $\mathrm{Km}^{2}$ with a population of 598,252 and a population density of 656 persons per $\mathrm{Km}^{2}$ according to (KNBS, 2009).

\section{Plant materials collection}

Acmella caulirhiza and Spermacoce princeae medicinal plant specimen were collected from West Mugirango and North mugirango constituencies in Nyamira County with acceptable bio-conservation methods (WHO, 2003a). Harvesting was done in a dry weather morning after the dew had evaporated (Prajapati et al., 2010). The two specimens were carried separately in gunny bags and transported to Pharmacognosy Laboratory of Mount Kenya University within 72 hours of collection (WHO, 2003a).

\section{Processing of plant materials}

Processing was done within 72 hours after collection. Herbarium preparations were established and the voucher specimens were processed in duplicate. They were mounted on herbarium sheets, pressed to flatten, to dry and were labeled. Voucher specimen (Number JN001 and JN002) were identified at East African Herbarium in the National Museums of Kenya on basis of morphological characteristics and compared with the voucher specimens recorded in East Africa Herbarium. Voucher specimen (Number JN001 and JN002) were deposited at Mount Kenya University Botanical Herbarium Laboratory in the school of Pharmacy. The collected materials were washed thoroughly with tap water and then air dried under a shade at room temperature for one week. When dried, the plant materials (A. caulirhiza and S. princeae were ground into course powder using a porcelain mortar and pestle (Hena, et al., 2010). The course powder materials were labeled and stored in brown paper bags under a dry condition, away from light at room temperature till the time of extraction and phytochemical screening (Prajapati et al., 2010).

\section{Plant extraction using organic solvents}

Using a top loading Weighing Electronic Balance (Models TP-B 2000), 50 grams of the Kenyan Acmella caulirhiza and 50 grams Spermacoce princeae each powder was weighed separately and transferred into separate conical flasks, labeled with the constituency of collection, plant species and date. Then 500mls of 100\% Ethyl Acetate (Loba Chemie Company Lot\#L157601502) was added to cover each plant materials and covered with a stopper, then macerated in the solvent at room temperature for 48 hours with intermittent agitation. Using a funnel and Whatman filter paper No. 1 the crude extracts from each of the plant materials were strained separately into glass reagent bottles then covered with stoppers. The process was repeated with 500mls of 100\% Ethanol Analar Normapur (VWR Prolabo Company Batch 12D250511) and Methanol (Loba Chemie Company Lot \#B193331604). The filtrates were labeled and concentrated in a rotary evaporator at 40 degree Celsius for Ethyl acetate, 60 degree Celsius for Ethanol and Methanol respectively. Using analytical balance, empty beakers were weighed, the extracts from the distillation flask were transferred into them, labeled appropriately and the solvents were evaporated in an Oven set at appropriate temperature. Quantity of each crude plant extract paste was calculated by the formula: Plant crude residue $=$ (weight of beaker + extract) - (weight of empty beaker). The extracted paste of each plant species examined was kept in beakers covered in a refrigerator a waiting for bioactivity assay (Afolayan et al., 20008).

\section{Aqueous extraction of crude plant material}

Aqueous extracts of Acmella caulirhiza and Spermacoce princeae was made from crude plant material according to Bibi et al.,(2012) by weighing 20 grams of Acmella caulirhiza and 20 grams of Spermacoce princeae. They were boiled separately in 400mls 
distilled water in beakers of $400 \mathrm{ml}$ capacity on Hot Plate set at $100^{\circ} \mathrm{C}$ for 5 minutes. The extracts were cooled, using a funnel and Whatman filter paper (No. 1) they were filtered and freeze dried according to Pikal et al., (2010), to extract dry powders from the aqueous solutions of the two plants. Freeze-drying was done in the following steps; freezing, primary drying and secondary drying. Primary drying involves; evacuating the system, increasing shelf temperature resulting to product temperature $2-3^{0} \mathrm{C}$ below collapse temperature. Secondary drying involves; removing unfrozen water from the solute phase by desorption through raising temperatures. The dry and lyophilized extracts were weighed and stored in a freezer for bioactivity testing (Bibi et al., 2012).

\section{Clinical samples collection}

Convenient sampling was used to select postpartum mothers from entire target population who were attending postnatal clinic. Participants who met inclusion criteria were informed on the study aspect and those who signed informed consent form were recruited. A single high vaginal swab was collected from each participant using a sterile cotton swab at Nyamira Level 5 Hospital. Swabbing activity was done at the nutrition/ immunization room by inserting the swab into posterior fornix of the vagina, rotating it for at least 10 seconds before withdrawing (WHO, 2003b). This was done in triplicate and immediately the swabs were inserted in Stuart Transport Medium (Oxoid, CM0111; UK) (Barber et al., 1998). They were labeled with the participant identification number and the date of collection and then inserted in the cooler box. Collected swabs were transported to Microbiology laboratory of Mount Kenya University within 48 hours where they were cultured immediately according to Feng et al., (2011). Sampling was done daily until desired number of participants was achieved.

\section{LABORATORY CLINICAL ANALYSIS}

All the swab specimens were separately aseptically mixed and diluted with normal saline in readiness for microbial isolations and characterization on arrival in the Research Microbiology laboratory in Mount Kenya University.

\subsubsection{Bacteria and Fungi Isolation and Characterization \\ 3.8.1.1 Staphylococcus species}

Inoculum was streaked on Nutrient agar (Oxoid, UK) in a lamina air flow hood. The plates were labeled with the name of the culture medium, participant identification number. The plates were incubated aerobically at $37^{\circ} \mathrm{C}$ for $18-24$ hours. After an overnight, gram stain was done on the growth. Then the isolates were sub cultured into mannitol salt agar (Oxoid, UK) and the plates were incubated aerobically at $37^{\circ} \mathrm{C}$ for 24 hours. Then sub cultured into nutrient agar (Oxoid, UK) and re-incubated aerobically at $37^{\circ} \mathrm{C}$ for 24 hours after which biochemical tests such as catalase and coagulase test were conducted to identify Stapylococcus aureus species (Gayle and Reginald, 2016).

\subsubsection{Escherichia species}

Inoculum was streaked on Nutrient agar (Oxoid, UK) plates in a lamina air flow hood. The plates were labeled with the name of the culture medium, participant identification number and the date. The plates were incubated aerobically at $37^{\circ} \mathrm{C}$ for $18-24$ hours. Identification of the bacteria was done based on their colonial morphology and Gram staining characteristics. Then the isolates were sub cultured into macConkey agar (Oxoid, UK) and the plates were incubated aerobically at 37 degree Celsius for 24 hours. Then biochemical tests such as motility, indole lysine decarboxylation, lysine deaminase in motility indole lysine medium, glucose fermentation and gas production in triple sugar iron agar slant and citrate utilization in citrate agar slant, were conducted to identify Escherichia coli species (Feng et al., 2011).

\subsubsection{Candida species}

Inoculum was streaked on sabouraud dextrose agar (Oxoid, UK) in a lamina air flow hood. The plates were labeled with the name of the culture medium, participant identification number and the date. The plates were incubated aerobically at $25^{\circ} \mathrm{C}$ for 3 days after which, grams stain and germ tube test were done (Cheesbrough, 2006). Then the yeast isolates were sub cultured onto chromogenic candida agar (Oxoid, CM 1002) plates and then sub cultured into corn meal agar (Oxoid, UK). Lastly, biochemical test was done using API Candida System to identify Candida albicans species. Budding yeast cells (Gram stain) indicates Candida species (Haw et al., 2012).

\subsection{Germ tube test}

Small test tubes were labeled with participant identification number and $0.5 \mathrm{ml}$ human serum was inoculated with suspected Candida cultures colony and then incubated aerobically at $37^{\circ} \mathrm{C}$ for 2 hours. After incubation, a drop of serum yeast culture was placed on a glass slide using a Pasteur pipette and covered with a cover slip then examined using x10 and x 40 objectives with condenser iris diaphragm closed to give good contrast for germinating blastospores (Kumar, 2010).

\subsection{Candida albicans colonies on CHROMagar Candida}

CHROMagar Candida is a chromogenic medium for speedy identification of Candida species within 24 to 48 hours on basis of colony colors (Odds and Davidson, 2000). On this medium Candida albicans forms green colonies. This medium differentiates $C$. albicans from other Candida species. This medium provides presumptive identifications of C. albicans (Odds and Davidson, 2000; Dilek et al., 2012). Chromogenic candida agar (Oxoid, CM 1002) plates were prepared according to the manufacturers' instructions. The plates were labeled with the name of the culture medium, participant identification number. Using inoculating loop, a single colony from a pure culture was inoculated onto chromogenic candida agar (Oxoid, $\mathrm{CM} 1002$ ) media and incubated at $35^{\circ} \mathrm{C}$ for $2-3$ day (Dilek et al., 2012). 


\subsection{Test for Chlamydospore formation on Corn Meal Agar}

Corn meal agar stimulates sporulation, suppressing certain other fungal growth and promotes morphological features in C. albicans and differentiates it from other Candida species. A significant characteristic of Candida albicans is the capability to form chlamydospores on corn meal agar which is significant in identification of Candida albicans (Michael and Burton, 2011).

Corn meal agar (Oxoid, UK) plates were prepared according to the manufacturers' instructions in a lamina flow hood. The plates were labeled with the name of the culture medium, participant identification number and the date. The yeast cultures were inoculated on corn meal agar (Oxoid, UK). The plates were incubated aerobically at $25^{\circ} \mathrm{C}$ for 3 days. After incubation a colony from the culture was picked and prepared on a glass slide then, was covered with a cover slip and examined using x10 and x 40 objectives with condenser iris diaphragm closed suitably to give good contrast. Chlamydospores which appear thick-walled at the ends of pseudohyphae, large and round indicates Candida albicans. Also pseudohyphae (budding yeast cells in chains) that produce clusters of asexual blastoconidia which are round at the cell junctions shows Candida albicans (Michael and Burton, 2011).

\subsection{Biochemical identification of fungi}

A commercial Analytical Profile Index (API) Candida System for the identification of yeasts (BioMérieux, France) was used to confirm the species of isolated yeast. A total of 12 biochemical tests were performed using this system. API Candida is a standard used to identify 18-24 hours yeasts. It consist 10 tubes containing dehydrated substrates, which allow 12 identifications which entail sugar acidification or enzymatic reactions to be performed. The end point of these reactions is the color change which is read visually following the Reading Table and referring to the list of profiles in the package insert.

Preparation of the inoculum: Yeast suspensions were prepared from 18-24 hours culture of Sabouraud dextrose agar (Oxoid, UK) plates. Using a wire loop, three well isolated and identical colonies were picked and emulsified in an ampule of API Sodium chloride $0.85 \%$ Medium $(2 \mathrm{ml})$. Yeast suspension whose turbidity equivalent to $3 \mathrm{McFarland}$ were prepared and they were compare with a turbidity control. These suspensions were used immediately after preparation. Strip [incubation box (tray and lid)] preparation was done according to the manufactures' instructions. To create a moist atmosphere, distilled water $(5 \mathrm{ml})$, was spread into the tray (honey-combed wells). The strip was inserted in the incubation box and tilting incubation box slightly forward (Monget et al., 1995).

Inoculation of the strip: Inoculum was distributed into each tube of the test strip using a pipette avoiding formation of bubbles by position the pipette on the edge of the cupule. The first 5 tests (GLU to RAF) and the last test (URE) were covered with mineral oil. Immediately after inoculation, incubation box was covered and aerobically incubated at $38^{\circ} \mathrm{C}$ for $18-24$ hours. Negative control was set containing a strip inoculated with sterile distilled water (Monget et al., 1995).

\subsection{Reading and Interpretation of API Candida System test Results}

After 18-24 hours of incubation, API Candida system results was read based on color change in each test strip, confirming from the reading table in the package insert and recording them on result sheet (as + or - ) provided by the manufacture (Monget et al., 1995).

\subsection{Determination of Antimicrobial Activity of the two plants extracts}

\subsubsection{Determination of Antibacterial Activity}

In vitro antibacterial activities of plant extracts was evaluated using Kirby-Bauer technique Bauer, (1998) based on traditional uses of the two plants by disc diffusion method using Escherichia coli and Staphylococcus aureus clinically isolated from Nyamira County Referral Hospital. ATCC 25923 (S. aureus) and ATCC 25922 (E. coli) from Kenya Medical Research Institute were used for quality control.

Inoculum was prepared using direct colony suspension method (EUCAST, 2015). Using a sterile loop, four morphologically similar colonies from overnight cultures (18-24 hours) were picked and suspended in 5ml sterile physiological saline (Sodium chloride 0.85\%) in separate test tubes for Escherichia coli and Staphylococcus aureus. A smooth suspension of the content was made using a vortex mixer (EUCAST, 2015). They were diluted with sterile physiological saline and their turbidity adjusted using UV-Visible Spectrophotometer (model; T60U PG Instrument) $\left\{\mathrm{OD}_{625 \mathrm{~nm}} 0.08-0.12\right.$ (1 $\mathrm{cm}$ light path) $\}$ to match 0.5 MacFarland standard (EUCAST, 2015). This obtained a microbial suspension of (1-2) x $10^{8} \mathrm{CFU} / \mathrm{mL}$ for both bacterial. Mueller Hinton agar plates were labeled and inoculated within 15 minutes of adjusting the turbidity. The lid was left ajar for 3 - 10 minutes at room temperature in laminar hood to allow any excess surface moisture to be absorbed.

Discs of $6 \mathrm{~mm}$ diameter were obtained by cutting Whatman No. 1 filter-paper (Maidstone, UK) using a paper punch. They were put in a bijou bottle, wrapped in aluminum foil paper and autoclaved at $121{ }^{\circ} \mathrm{C}$ for 15 minutes. Each disc was impregnated with $20 \mu 1$ of each plant extract at varying concentration of $100 \mathrm{mg} / \mathrm{ml}-500 \mathrm{mg} / \mathrm{ml}$ (Dora et al., 2012). The coated discs on petri dishes separately were covered and left in aseptic condition under the laminar air flow to dry. The discs were aseptically transferred to the inoculated plates using sterile forceps. A volume $(20 \mu \mathrm{L})$ dimethyl Sulphoxide solvent was used as a negative control for Staphylococcus aureus and Escherichia coli. Ceftriaxone $(30 \mu \mathrm{g})$ was used as positive controls for Escherichia coli while Co-trimoxazole $(25 \mu \mathrm{g})$ was used as positive controls for Staphylococcus aureus. Finally, agar plates were labeled, inverted and incubated at $37^{\circ} \mathrm{C}$ for 24 hours (EUCAST, 2015). Experiments were done in triplicate. Inhibition zones were determined and the mean values of the three replicates recorded to the nearest whole millimeter.

\subsubsection{Determination of Antifungal Activity of the two plants extracts}

In vitro antifungal activity of the two plant extracts were evaluated using Kirby-Bauer technique Bauer, (1998) based on traditional uses of the two plants by disc diffusion method using Candida albicans clinically isolated from Nyamira County Referral Hospital. American Type Cultures Collections (ATCC 90028) of Candida albicans from Kenya Medical Research Institute were used for quality control. Antifungal activity was done on Mueller-Hinton agar (Oxoid UK). 
Inoculum was prepared using direct colony suspension method (EUCAST, 2015). Using a sterile loop, four morphologically similar colonies from overnight cultures (24 hours) on Sabouraud dextrose agar (Oxoid UK) were picked and suspended in $5 \mathrm{ml}$ sterile physiological saline (Sodium chloride $0.85 \%$ ) in test tubes. A smooth suspension of the content was made using a vortex mixer (EUCAST, 2015). It was diluted with sterile physiological saline and the turbidity was adjusted using UV-Visible Spectrophotometer (model; T60U PG Instrument) $\left\{\mathrm{OD}_{625 \mathrm{~nm}} 0.08-0.12\right.$ (1 cm light path) $\}$ to match $0.5 \mathrm{MacFarland}$ standard (EUCAST, 2015). This obtained a yeast suspension concentration of (1-5) x $10^{6} \mathrm{CFU} / \mathrm{mL}$ for Candida albicans (EUCAST, 2015).

Mueller Hinton agar plates were labeled and inoculated within 15 minutes of adjusting the turbidity. The lid was left ajar for 3 10 minutes at room temperature in laminar hood to allow any excess surface moisture to be absorbed.

Discs of $6 \mathrm{~mm}$ diameter were obtained by cutting Whatman No. 1 filter-paper (Maidstone, UK) using a paper punch. They were put in a bijou bottle, wrapped in aluminum foil paper and autoclaved at 121 degree Celsius for 15 minutes. Each disc was impregnated with $20 \mu \mathrm{l}$ plant extract at a concentration of $100 \mathrm{mg} / \mathrm{ml}-500 \mathrm{mg} / \mathrm{ml}$ (Dora et al., 2012). The coated discs on Petri dishes separately were covered and left in aseptic condition under the laminar air flow to dry. The discs were aseptically transferred to the inoculated plates using sterile forceps. Dimethyl Sulphoxide solvent $(20 \mu \mathrm{L})$ was used as negative control while Nystatin (Himedia india, SD025-ICT) $(100 \mu \mathrm{g})$ was used as positive control for Candida albicans. The plates were labeled, inverted and incubated at $37^{0} \mathrm{C}$ for $20-24$ hours. Experiments were done in triplicate. The zone diameters were measured manually then the mean values of the three replicates recorded to the nearest whole millimeter (EUCAST, 2015).

\subsubsection{Measurement of inhibition zones and interpretation of results}

After incubation, antimicrobial potentials of crude plant extracts against test organisms were assessed by determining zones of inhibition (indicated by clear zones of growth inhibition) around the discs diameter (including the diameter of the disk) and recorded in millimeters using a ruler on the undersurface of the plate without opening the lid. The zones of inhibition diameter were measured to the margin of heavy growth. Then the zones of inhibition were compared with the zone-size interpretative of standard growth inhibition zones and recorded as susceptible, intermediate, or resistant to each crude drug according to inhibition size (CLSI, 2015).

\section{Data Analysis and Presentation}

The questionnaires were checked for completeness at the end of each data collection session. Data was stored in Excel spread sheet in a personal computer protected with a password. Also a flash disk secured with a password was used as a backup. After incubation, the zones of inhibition diameter were measured in $\mathrm{mm}$ and the averages results of the triplicate experiments were calculated. Activity of each extract was interpreted as; < $6 \mathrm{~mm}$ no activity, $6.1 \mathrm{~mm}-8 \mathrm{~mm}$ little activity), $8.1 \mathrm{~mm}-10 \mathrm{~mm}$ moderate activity, $11 \mathrm{~mm}-12 \mathrm{~mm}$ active, $>12 \mathrm{~mm}$ very active. The Data was presented using tables.

\subsection{Ethical Considerations}

Ethical clearance was obtained from Mount Kenya University E.R.C, NACOSTI and Nyamira Level 5 Hospital before commencement of the study. Participants who met inclusion criteria were informed on the study aspects. Only those who signed informed consent form were included in the study and confidentiality was maintained. Antimicrobial activity was done in Microbiology laboratory in M.K.U Research Centre while plant processing was conducted in M.K.U Pharmacognosy laboratory. Findings

\section{Characterization of Clinical Isolates Causing PostPartum Infections}

Out of 339 samples examined, $18.29 \%$ postpartum mothers were infected whereas $81.71 \%$ remaining postpartum mothers had no potential pathogens isolated. Microbial isolates of gram positive S. aureus (8.26\%), gram negative E. coli (4.13\%) and fungi C. albicans $(5.9 \%)$ were isolated from the postpartum mothers.

\subsubsection{Staphylococcus species}

The characterization and identification of Staphylococcus spp. was done according to Gayle and Reginald, (2016) and Chesbrough (2006) methods. It was determined that Staphylococcus aureus was one of the causative agent of postpartum.

\subsubsection{Escherichia species}

The characterization and identification of Escherichia spp. was done according to Feng et al., (2011) and Cheesbrough (2006). It was determined that Escherichia coli was one of the causative agent of postpartum.

\subsubsection{Candida species}

The characterization and identification of Candida spp. was done according to Haw et al., (2012) and Cheesbrough (2006). Germ tube test was done according to Kumar, (2010). The yeast were sub-cultured on chromogenic candida agar according to Odds and Davidson, (2000) and Dilek et al., (2012). Chlamydospore formation was done on corn meal agar according to Michael and Burton, (2011). Analytical Profile Index (API) Candida System (BioMérieux, France) was used to identify Candida species according to Monget et al., (1995). It was determined that Candida albicans was one of the causative agent of postpartum and the isolate had a profile number; 7002, Table 4.1 obtained with the API Candida System test strip, was identified as Candida albicans. 


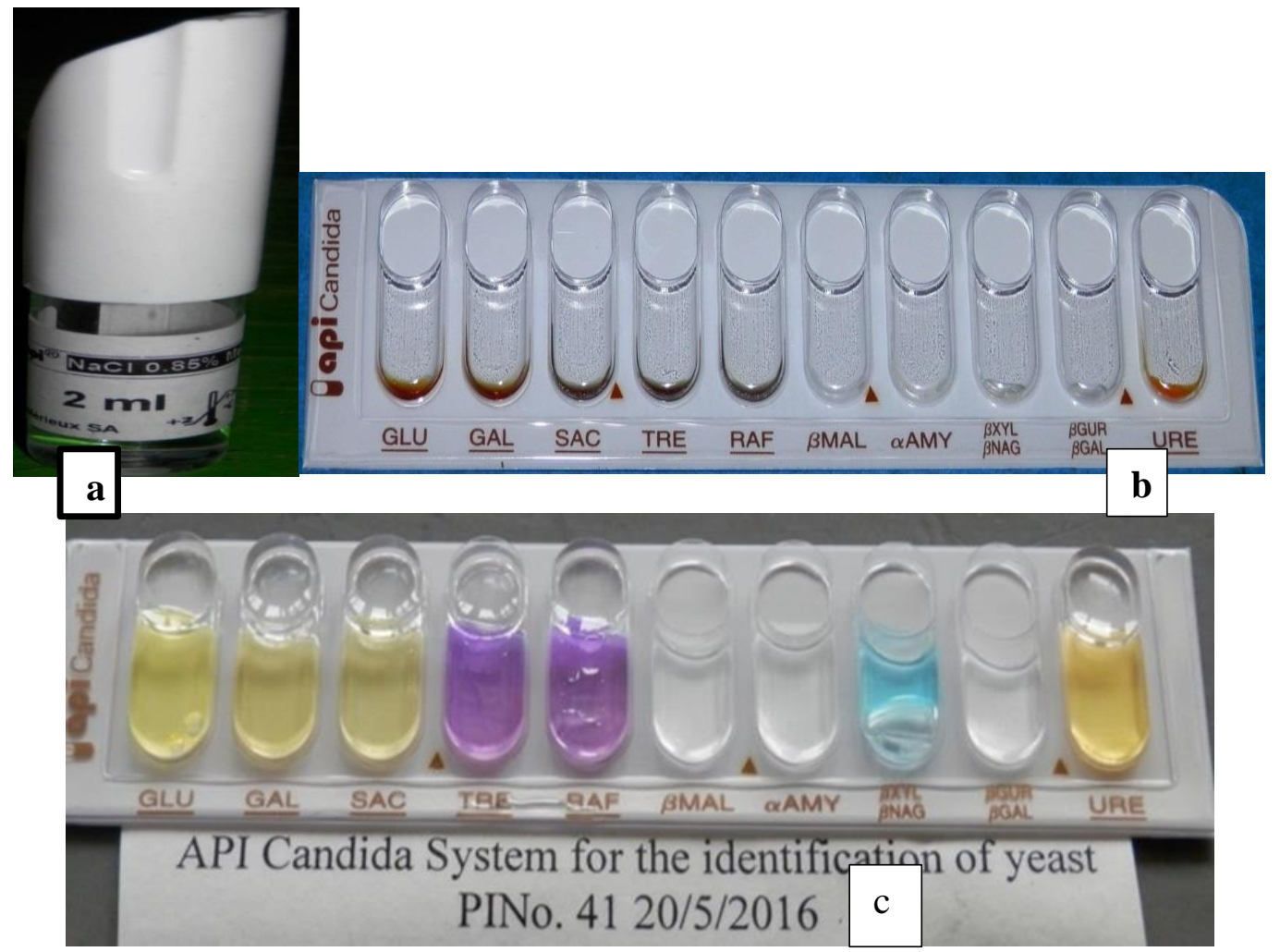

Plate 4.1: API Candida System for C. albicans Identification

a) Shows API suspension medium (BioMérieux, France)

b) Shows API Candida System test strip (BioMérieux, France)

c) Candida albicans Reaction on API Candida System kit (BioMérieux, France)

Table 4.1: Candida albicans result codes from API Candida System kit test

\begin{tabular}{|l|l|l|l|l|l||l|l|l|l|l|l|}
\hline \multicolumn{10}{|c|}{ API Candida System Result sheet coded } \\
\hline 1 & 2 & 3 & 4 & 5 & 6 & 7 & 8 & 9 & 10 & 11 & 12 \\
\hline+ & + & + & - & - & - & - & - & - & - & + & - \\
\hline 1 & 2 & 4 & 1 & 2 & 4 & 1 & 2 & 4 & 1 & 2 & 4 \\
\hline$\underline{\text { GLU }}$ & $\underline{\text { GAL }}$ & $\underline{\mathrm{SAC}}$ & $\underline{\mathrm{TRE}}$ & $\underline{\mathrm{RAF}}$ & $\beta \mathrm{MAL}$ & $\alpha \mathrm{AMY}$ & $\beta \mathrm{XYL}$ & $\beta \mathrm{GUR}$ & $\underline{\mathrm{URE}}$ & $\beta \mathrm{NAG}$ & $\beta \mathrm{GAL}$ \\
\hline
\end{tabular}

Table 1a: Antibacterial Activity of $A$. caulirhiza against $S$. aureus and $E$. coli

\section{Acmella caulirhiza}

\begin{tabular}{|c|c|c|c|c|c|c|c|c|}
\hline & Extracts & $\begin{array}{l}\text { Negative control } \\
20 \mu \mathrm{l}\end{array}$ & $\begin{array}{l}100 \\
\mathrm{mg} / \mathrm{ml}\end{array}$ & $\begin{array}{l}200 \\
\mathrm{mg} / \mathrm{ml}\end{array}$ & $\begin{array}{l}300 \\
\mathrm{mg} / \mathrm{ml}\end{array}$ & $\begin{array}{l}400 \\
\mathrm{mg} / \mathrm{ml}\end{array}$ & $\begin{array}{l}500 \\
\mathrm{mg} / \mathrm{ml}\end{array}$ & $\begin{array}{l}\text { Co-trimoxazole } \\
\text { (CT) } 25 \mu \mathrm{g}\end{array}$ \\
\hline S. aureus & Aqueous & 6 & 6 & 6 & 6 & 6 & 6 & 25 \\
\hline
\end{tabular}




\begin{tabular}{|c|c|c|c|c|c|c|c|c|}
\hline & Ethyl acetate & 6 & 6 & 6 & 6 & 6 & 6 & 25 \\
\hline \multirow{6}{*}{ E. coli } & Ethanol & 6 & 7.1 & 7 & 7.3 & 7.6 & 8 & 25 \\
\hline & Methanol & 6 & 6 & 6 & 7 & 7.3 & 8 & $\begin{array}{l}25 \\
\text { Ceftriaxone } \\
\text { (FR) } 30 \mu \mathrm{g}\end{array}$ \\
\hline & Aqueous & 6 & 6 & 6 & 6 & 6 & 6 & 21 \\
\hline & Ethyl acetate & 6 & 6 & 6 & 6 & 6 & 6 & 21 \\
\hline & Ethanol & 6 & 6.1 & 6.8 & 7.3 & 7 & 6.6 & 21 \\
\hline & Methanol & 6 & 6 & 6 & 6 & 6.6 & 6.3 & 21 \\
\hline
\end{tabular}

Antibacterial activity of A. caulirhiza extracts against S. aureus, E. coli (isolates), S. aureus (ATCC 25923) and E. coli (ATCC 25922) indicated a similar results.

Table 1b: Antibacterial Activity of S. princeae against S. aureus and E. coli

\section{Spermacoce princeae}

\begin{tabular}{|c|c|c|c|c|c|c|c|c|}
\hline & Extracts & $\begin{array}{l}\text { Negative } \\
\text { control } 20 \mu \mathrm{l}\end{array}$ & $\begin{array}{l}100 \\
\mathrm{mg} / \mathrm{ml}\end{array}$ & $\begin{array}{l}200 \\
\mathrm{mg} / \mathrm{ml}\end{array}$ & $\begin{array}{l}300 \\
\mathrm{mg} / \mathrm{ml}\end{array}$ & $\begin{array}{l}400 \\
\mathrm{mg} / \mathrm{ml}\end{array}$ & $\begin{array}{l}500 \\
\mathrm{mg} / \mathrm{ml}\end{array}$ & $\begin{array}{l}\text { Co-trimoxazole } \\
\text { (CT) } 25 \mu \mathrm{g}\end{array}$ \\
\hline \multirow[t]{5}{*}{ S. aureus } & Aqueous & 6 & 6 & 6 & 6 & 6 & 6.3 & 25 \\
\hline & Ethyl acetate & 6 & 6 & 6 & 6 & 6 & 6 & 25 \\
\hline & Ethanol & 6 & 6 & 6.3 & 7 & 6.6 & 6.3 & 25 \\
\hline & Methanol & 6 & 6 & 6 & 6.3 & 7.6 & 7.3 & 25 \\
\hline & & & & & & & & $\begin{array}{l}\text { Ceftriaxone } \\
\text { (FR) } 30 \mu \mathrm{g}\end{array}$ \\
\hline \multirow[t]{4}{*}{ E. coli } & Aqueous & 6 & 6 & 6 & 6 & 6 & 6.5 & 21 \\
\hline & Ethyl acetate & 6 & 6 & 6 & 6 & 6 & 6 & 21 \\
\hline & Ethanol & 6 & 7 & 8.3 & 8 & 8 & 6.6 & 21 \\
\hline & Methanol & 6 & 6 & 6 & 7 & 7 & 6.3 & 21 \\
\hline
\end{tabular}

Antibacterial activity of S. princeae extracts against S. aureus, E. coli (isolates), S. aureus (ATCC 25923) and E. coli (ATCC 25922) indicated a similar results 
Table 1c: Antifungal Activity of A. caulirhiza and S. princeae against $C$. albicans

\section{Candida albicans}

\begin{tabular}{|c|c|c|c|c|c|c|c|c|}
\hline & Extracts & $\begin{array}{l}\text { Negative control } \\
20 \mu \mathrm{l}\end{array}$ & $\begin{array}{l}100 \\
\mathrm{mg} / \mathrm{ml}\end{array}$ & $\begin{array}{l}200 \\
\mathrm{mg} / \mathrm{ml}\end{array}$ & $\begin{array}{l}300 \\
\mathrm{mg} / \mathrm{ml}\end{array}$ & $\begin{array}{l}400 \\
\mathrm{mg} / \mathrm{ml}\end{array}$ & $\begin{array}{l}500 \\
\mathrm{mg} / \mathrm{ml}\end{array}$ & $\begin{array}{l}\text { Nystatin } \\
\text { (NS) } 100 \mu \mathrm{g}\end{array}$ \\
\hline \multirow[t]{4}{*}{ A. caulirhiza } & Aqueous & 6 & 6 & 6 & 6 & 6 & 6 & 25 \\
\hline & Ethyl acetate & 6 & 6 & 6 & 6 & 6 & 6 & 25 \\
\hline & Ethanol & 6 & 6 & 6 & 6 & 6 & 6 & 25 \\
\hline & Methanol & 6 & 6 & 6 & 6 & 6 & 6 & 25 \\
\hline \multirow[t]{4}{*}{ S. princeae } & Aqueous & 6 & 6 & 6 & 6 & 6 & 6 & 25 \\
\hline & Ethyl acetate & 6 & 6 & 6 & 6 & 6 & 6 & 25 \\
\hline & Ethanol & 6 & 6 & 6 & 6 & 6 & 6 & 25 \\
\hline & Methanol & 6 & 6 & 6 & 6 & 6 & 6 & 25 \\
\hline
\end{tabular}

Antifungal activity of A. caulirhiza and S. princeae extracts against C. albicans isolates and C. albicans (ATCC 90028) indicated a similar result.

\section{DISCUSSION}

Medicinal plants usage is increasingly popular among the Gusii community of Nyamira County. Many medicinal plants grow around the homestead and have been used naturally for many years by traditional healers to control common health problems. Antimicrobial drug discovery from natural medicinal plants are expected to be effective against multi drug resistant microorganisms (Gemechu et al., 2015).

\section{Characterization of Clinical Isolates Causing Postpartum Infections}

Staphylococcus aureus was characterized and identified by culture, gram stain, biochemical techniques and serology. Thus, it was identified as one of the causative agent of postpartum infections. Other findings corroborate this finding that $S$. aureus is the common microorganism isolated from postpartum mothers (Bako et al., 2012; Nahid et al., 2009).

Escherichia coli was characterized and identified by isolating it in pure form using nutrient agar, and using selective/ differential growth condition such as macConkey agar. Staining reaction on gram stain was used to differentiate gram negative from gram positive and to identify the shape of bacteria. Colonial morphology of $E$. coli was identified and cultural characteristics were also observed. Metabolism involving the requirement of oxygen and the capacity to form pigments and biochemical techniques were performed. Thus E. coli was identified as one of the causative agent of postpartum infections. Other findings have reported that $E$. coli is the common microorganism isolated from postpartum mothers (Bako et al., 2012; Nahidet al., 2009).

Candida albicans was characterized and identified by culture, gram stain and germ tube test. The yeasts were sub-cultured on chromogenic candida agar then on corn meal agar to differentiate $C$. albicans based on colony colors and chlamydospore formation respectively. C. albicans colonies appeared green indicating a positive result. On corn meal agar, chlamydospores appeared thick-walled at the ends of pseudohyphae, large and round. Budding resulted in chains of cells called pseudohyphae that produced clusters of round, asexual blastoconidia at the cell junctions were observed. Analytical Profile Index (API) Candida System was used to identify Candida species. The reactions obtained were coded into numerical profile groups of three where by 1, 2 or 4 was assigned to each one. A 4-digit numerical profile was obtained by adding together the numbers corresponding to the positive reactions within each group. The isolate with profile number: 7002 obtained with the API Candida System test strip was identifies as Candida albicans. It was determined that Candida albicans was one of the causative agent of postpartum infection. Other findings have reported that Candida albicans cause 6.8\% microbial urinary tract infections related to postpartum infections (Payam et al., 2010). 
Other studies have indicated that micro-organisms causing postpartum infections are indigenous to the female genital tract (Nahid et al., 2009). This is justified from this study because mixed bacterial and fungal agents were isolated from high vaginal specimen and this implicates endometritis diagnosis in women clients. This has a significant public health consequence since physicians, frequently face difficulties of knowing exact cause of postpartum infections in the process of giving the right treatment.

In this study, postpartum infections were prevalent because out of 339 participants examined, $18.29 \%$ (62 persons) postpartum mothers were infected whereas $81.71 \%$ had no potential pathogens isolated. Gram positive $S$. aureus $(8.26 \%)$, gram negative E. coli (4.13\%) and fungi $C$. albicans $(5.9 \%)$ were isolated. This finding concurs with those of Ahnfeldt-Mollerup, (2012), who reported that puerperal sepsis prevalence was between $5-24 \%$ depending on the different socio-cultural conditions.

\section{Antibacterial Activity of Acmella caulirhiza and Spermacoce princeae against $S$. aureus and $E$. coli}

Neighter aqueous nor ethyl acetate crude plant extracts of $A$. caulirhiza indicated antibacterial activity against $S$. aureus and $E$. coli in contrast to positive controls. Although aqueous plant extract is mostly used, alcoholic solvents have been reported to provide consistent activity (Das et al., 2010). Ethanol and methanol crude plant extracts of $A$. caulirhiza indicated that they had low activity against $S$. aureus and $E$. coli.

A. caulirhiza ethanol crude plant extract indicated its highest antibacterial activity at concentration $500 \mathrm{mg} / \mathrm{ml}(8 \mathrm{~mm})$ and its lowest activity at concentration $200 \mathrm{mg} / \mathrm{ml}(7 \mathrm{~mm})$ against $S$. aureus. While it indicated its highest antibacterial activity at concentration $300 \mathrm{mg} / \mathrm{ml}(7.3 \mathrm{~mm})$ and its lowest activity at concentration $100 \mathrm{mg} / \mathrm{ml}(6.1 \mathrm{~mm})$ against E. coli. This means ethanol crude plant extract of $A$. caulirhiza has low activity against $S$. aureus and $E$. coli. Antibacterial activity with the increase of the concentration observed is in agreement with the earlier studies (Banso and Adeyemo, 2007).

Similarly, methanol crude plant extract of A. caulirhiza indicated its highest antibacterial activity at concentration $500 \mathrm{mg} / \mathrm{ml}$ $(8 \mathrm{~mm})$ and its lowest activity at concentration $300 \mathrm{mg} / \mathrm{ml}(7 \mathrm{~mm})$ against $S$. aureus. While it indicated its highest antibacterial activity at concentration $400 \mathrm{mg} / \mathrm{ml}(6.6 \mathrm{~mm})$, its lowest activity was at concentration $500 \mathrm{mg} / \mathrm{ml}(6.3 \mathrm{~mm})$ against $E$. coli. This means A. caulirhiza methanol crude plant extract has low activity against $S$. aureus and E. coli. The results of this study corroborate and/or oppose data reported in literature. Kipruto et al. 2013, conducted a study which opposes the finding of the present study in which $A$. caulirhiza chloroform extract indicated inhibitory effects against $S$. aureus and E. coli, whereas Bethwell (2012), found no antibacterial activity of methanol extracts of $A$. caulirhiza against $S$. aureus and $E$. coli. In reference to positive controls co-trimoxazole at concentration $25 \mu \mathrm{g}$ had the highest antibacterial activity $(25 \mathrm{~mm})$ for $S$. aureus while ceftriaxone had highest antibacterial activity at concentration $30 \mu \mathrm{g}$ $(21 \mathrm{~mm})$ for $E$. coli hence commercially available antibiotics are still effective as compared to crude plant extracts.

Antibacterial activity of ethyl acetate crude plant extract of $S$. princeae indicated no antibacterial activity against $S$. aureus and $E$. coli in contrast to positive controls. However, aqueous crude plant extract of the same plant at higher concentration (500mg/ml) indicated low antibacterial activity $(6.3 \mathrm{~mm}$ and $6.5 \mathrm{~mm}$ zone of inhibition) against $S$. aureus and E. coli respectively. This point out that, aqueous crude plant extract of this plant has little activity against $S$. aureus and $E$. coli at higher concentration. On the other hand, ethanol crude plant extracts of $S$. princeae indicated a moderate antibacterial activity against $S$. aureus and E. coli from concentration $200 \mathrm{mg} / \mathrm{ml}$ onwards. An antibacterial effect with the increase of the concentration observed is in agreement with the earlier studies (Mahmoud $e t$ al., 2014). Similarly, methanol crude plant extracts of $S$. princeae indicated a moderate antibacterial activity against $E$. coli and $S$. aureus from concentration $200 \mathrm{mg} / \mathrm{ml}$ and $300 \mathrm{mg} / \mathrm{ml}$ onwards respectively. This indicates that even if this plant is used during postpartum, the plant has little activity against $S$. aureus and E. coli.

S. princeae ethanol crude plant extract indicated its highest antibacterial activity at concentration $300 \mathrm{mg} / \mathrm{ml}(7 \mathrm{~mm})$ and its lowest activity at concentration $200 \mathrm{mg} / \mathrm{ml}$ and $500 \mathrm{mg} / \mathrm{ml}(6.3 \mathrm{~mm})$ against $S$. aureus. While it indicated its highest antibacterial activity at concentration $200 \mathrm{mg} / \mathrm{ml}(8.3 \mathrm{~mm})$ and its lowest activity was at concentration $500 \mathrm{mg} / \mathrm{ml}(6.6 \mathrm{~mm})$ against $E$. coli. This indicates that $S$. princeae ethanol crude plant extract has little activity against $S$. aureus and E. coli even if this plant is used during postpartum. Similarly, methanol crude plant extract of $S$. princeae indicated its highest antibacterial activity at concentration $400 \mathrm{mg} / \mathrm{ml}(7.6 \mathrm{~mm})$ and its lowest activity was at concentration $300 \mathrm{mg} / \mathrm{ml}(6.3 \mathrm{~mm})$ against $S$. aureus. While it indicated its highest antibacterial activity at concentration $300 \mathrm{mg} / \mathrm{ml}$ and $400 \mathrm{mg} / \mathrm{ml}(7 \mathrm{~mm})$ its lowest activity was at concentration $500 \mathrm{mg} / \mathrm{ml}(6.3 \mathrm{~mm})$ against E. coli. This indicates that, methanol crude plant extract of $S$. princeae has little activity against $S$. aureus and E. coli. In reference to positive controls, cotrimoxazole $25 \mu \mathrm{g}$ had the highest antibacterial activity $(25 \mathrm{~mm})$ for $S$. aureus while ceftriaxone had its highest antibacterial activity at concentration $30 \mu \mathrm{g}(21 \mathrm{~mm})$ for $E$. coli hence commercially available antibiotics are still effective as compared to crude plant extracts.

In general, ethanol was indicated as the best solvent in extracting active ingredients from these plants for antibacterial screening. These results are consistent with earlier reports that, $A$. caurhiza was active against $S$. aureus and it is used to treat toothache, sore throat, earache and stomachache (Kipruto et al., 2013). Other findings have shown that $S$. princeae water extracts of leaves and roots are used to treat wounds, eye problems, venereal diseases, skin diseases, pneumonia, typhoid and diarrhea (Jeruto et al., 2011). There was no significant difference between the clinical isolates (S. aureus and E. coli) and the standard S. aureus (ATCC 25923) and E. coli (ATCC 25922).

\subsubsection{Antifungal Activity of Acmella caulirhiza and Spermacoce princeae against Candida albicans.}

A. caulirhiza and $S$. princeae at concentration $100 \mathrm{mg} / \mathrm{ml} 200 \mathrm{mg} / \mathrm{ml}, 300 \mathrm{mg} / \mathrm{ml}, 400 \mathrm{mg} / \mathrm{ml}$ and $500 \mathrm{mg} / \mathrm{ml} \mathrm{indicated} \mathrm{no} \mathrm{antifungal}$ activity against $C$. albicans. These findings concur with other studies that $A$. caulirhiza does not have antifungal activity against $C$. albicans even at high concentration (Kipruto et al., 2013). In reference to positive control Nystatin at concentration $100 \mu \mathrm{g}$ had the 
highest antifungal activity $(25 \mathrm{~mm})$ for $C$. albicans hence commercially available antifungals are still effective as compared to crude plant extracts. There was no significant difference between the clinical isolates (C. albicans) and standard C. albicans (ATCC90028).

\section{CONCLUSION}

The two plants (A. caulirhiza and S. princeae) used by the local inhabitants of Nyamira County in treatment of child sores and to clean reproductive system after birth indicated that, they were not efficacacious but possess some antibacterial activity even though they are used in treatment of postpartum infections. Antibacterial activity of the two plants varied depending on the extraction solvent used. Aqueous and ethyl acetate extracts were the weakest extraction solvents though ethanol and methanol extraction solvents indicated they were the best solvents in obtaining activity from the two medicinal plants. Alcoholic extracts indicated some activity against $S$. aureus and E. coli. Ethanol extracts had the highest zone of inhibition while ethyl acetate extracts had the least zone of inhibition. Manifestation of antibacterial activity from the two medicinal plants investigated indicates that the two plants can be a potent source of alternative medicines. Plants based antimicrobials have enormous therapeutic potential. Acmella caulirhiza and Spermacoce princeae plants represent unexploited source of compounds with antimicrobial activity which could be a resource for development of natural therapeutic drugs. No antifungal activity was detected on the two medicinal plants. Antimicrobial activity evaluation lays a foundation for ethnobotanical and pharmacological investigations for new drug discovery.

\section{RECOMMENDATION}

Pregnant women are encouraged to deliver at the health facility to reduce morbidity and mortality caused by postpartum infections. The two plants may be used as medicine and can be a potent source of complementary and modern medicine although their antimicrobial activity is low. A. caulirhiza and $S$. princeae plants may be used in treating puerperal sepsis though commercially available drugs are recommended as they are highly effective. The two plants indicated some antibacterial activity against $S$. aureus and $E$. coli. However, further studies are recommended on genotoxicity of this plant extracts on $S$. aureus and E. coli genes. Also further research is recommended to isolate and identify pure compounds of the two plants to establish pharmacological basis of antibacterial activity shown even though it was low.

\section{ACKNOWLEDGMENT}

I am glad to almighty God for being with me through this far.

I am importantly grateful to my supervisors Dr. Jackson Odhiambo Onyuka from the school of Medicine, Department of Medical Laboratory Science, Mount Kenya University and Mr. Jared Misonge Onyancha from the School of Pharmacy, Department of Pharmacognosy, Mount Kenya University who strongly and patiently supervised this research project, giving me valuable guidance throughout this research thesis period. My appreciation goes to my immediate supervisor Mr. Masasi of Mount Kenya University health centre and my colleagues at work for encouraging me to work hard. May God bless them.

\section{REFERENCES}

[1] Afolayan, A. J., Ncube, N. S. and Okoh, A. I. (2008). Assessment techniques of antimicrobial properties of natural compounds of plant origin: Current methods and future trends. African Journal of Biotechnology 7 (12): 1797-1806.

[2] Ahnfeldt-Mollerup, P., Petersen, L. K., Kragstrup, J., Christensen, R. D. and Sorensen, B.(2012). Postpartum infections: occurrence, healthcare contacts and association withbreastfeeding. Acta Obstet Gynecol Scand

[3] Augustin, N. Donatien, G., Simeon, P. C. F. and Huguette, N. M. (2015). Toxicological Evaluation of the Aqueous Leaf Extract of Spermacoce princeae (Rubiaceae): A Traditional Antibacterial Preparation. International Journal of Toxicological and Pharmacological Research 7(3); 123-129.

[4] Antony, O. R., Michael, K., Makokha, A. O. and Festus, M. T. (2016). Types of Herbal Medicine Used for HIV Conditions in Vihiga County, Kenya. European Journal of Medicinal Plants 13(2): 1-23

[5] Bako, B., Audu, B. M., Lawan, Z. M. and Umar, J. B. (2012). Risk factors and microbial isolates of puerperal sepsis at the University of Maiduguri Teaching Hospital, Maiduguri, North-eastern Nigeria. Arch Gynecol Obstet; 285: 913-7.

[6] Banso, A. and Adeyemo, S. O. (2007). Evaluation of antibacterial properties of tannins isolated from Dichrostachys cinerea. Afr. J. Biotechnol. 6 (15), $1785-1787$.

[7] Barber, S., Lawson P. J. and Grove, D. I. (1998). Evaluation of Bacteriological Transport

Swabs. Pathology 30, pp. 179-182

[8] Bauer, R. (1998). Quality criteria and standardization of phytopharmaceuticals: Can acceptable drug standards be achieved? Drug Inf J. 32: 101-110.

[9] Berhane, K., Tinde, A., Laurentius, J. M. and Zemede, A. (2014). Use and management of traditional medicinal plants by Maale and Ari ethnic communities in southern Ethiopia. Journal of Ethnobiology and Ethnomedicine, 10:46

[10] Bethwell, O. O. (2012). Usage Consensus Study of Bioactivity of the Luo and Kuria Medical Ethnobotanies.

[11] Bibi, Y., Nisa, S., Zia M., Waheed, A., Ahmed, S. and Chaudhary, F. M. (2012). Invitro cytotoxicity activity of Aesculus indica against breast carcinoma cell lines (MCF-7) and phytochemical analysis. Pak. J. Pharm. Sci., 25 (1): 183-187 
[12] Cheesbrough, M. (2006). District Laboratory Practice in Tropical. 2nd Edition Cambridge University Press publishers, New York page $132-143$.

[13] Clinical and Laboratory Standard Institute (2015). Performance Standards for Antimicrobial Susceptibility Testing; 20th Informational Supplement. CLSI document M100-S19. CLSI, Wayne, PA: Clinical and Laboratory Standard Institute. CLSI January, 2007.

[14] Crouch1, L. A., Mulholland, D. A. and Nair, J. J. (2005) A novel alkylamide from the leaves of Acmella caulirhiza (Asteraceae), atraditional surface analgesic. South African journal 71(2): 228-230

[15] Das, K., Tiwari, R. K. and Shrivastava, D. K. (2010). Techniques for evaluation of medicinal plant products as antimicrobial agent: Current methods and future trends. J. Med. PlantsRes. 4 (2):104-111.

[16] Dilek, Y. M., Husnu, P., Suleyha, H. P., Ramazan, I. and Zekiye, E. T. (2012). Do incubation temperature, incubation time, and carbon dioxide affect the chromogenic properties ofCHROMagar?Turk J Med Sci 42 (6): 977-980

[17] European Committee on Antimicrobial Susceptibility Testing (2015). Antimicrobial susceptibility testing.

[18] Feng, P., Karen, J. and Weagant, S. D. (2011). Bacteriological analytical manual.http://www.fda.gov/Food/ Food Science Research /Laboratory Methods/ucm2006949.htm.

[19] Focho, D. A., Ndam W. T. and Fonge, B. A. (2009). Medicinal plants of Aguambu - Bamumbu Cameroon. African Journal of Pharmacy and Pharmacology Vol. 3 (1). pp. 001-013.

[20] Gayle, A. L. and Reginald W. B. (2016). Bacteriological analytical manual. http://www.fda.gov/Food/ FoodScienceResearch/LaboratoryMethods/ucm2006949.htm.

[21] Gemechu, A. B., Abdella, G. D. and Engda, D. (2015). Antimicrobial Activity of Lippia adoensis var. koseret Against Human Pathogenic Bacteria and Fungi. American Journal of Clinical and Experimental Medicine. 3(3): 118-123

[22] Haw, B. P., Venugopal, B., Eugene, O. Asma, I. and Sasidharan, S. (2012). Isolation andIdentification of Candida albicans to produce in house helicase for PCR. Annual International Conference.

[23] Hena, J. S. 1., Adamu, A.. K. L., Iortsuun, D. N. and Olonitola, O. S. (2010). Phytochemical Screening and Antimicrobial Effect of the Aqueous and Methanolic Extracts of Roots of Balanites aegyptiaca (Del.) On Some Bacteria Species. Science World Journal Vol 5 (No 2)

[24] Jeruto, P., Mutai, C., Catherine, L. and Ouma, G. (2011). Phytochemical constituents of some medicinal plants used by the Nandis of South Nandi district, Kenya. Journal of Animal and Plant Sciences; Vol. 9, Issue 3: 1201- 1210.

[25] Jeruto, P. Too, E. Mwamburia, L. A. and Amuka, O. (2015). An Inventory of Medicinal Plants used to Treat Gynaecological-Obstetric-Urino-Genital Disorders in South Nandi Sub County in Kenya. Journal of Natural Sciences Research ISSN 2224-3186 (Paper) Vol.5, No.18, 2015

[26] Kenya national bureau of statistics census (2009).

[27] Kipruto, A. Sinei., F. A., Okalebo, A., Hannington, N., Mugo, B. and Josephat, M. M. (2013). An Investigation of the Antimicrobial Activity of Acmella caulirhiza. African Journal of Pharmacology and Therapeutics Vol. 2 No. 4 Pages 130-133.

[28] Kokwaro, J. O. (2009). Medicinal plants of East Africa: East Africa Literature Bureaus Nairobi- $\quad$ Kenya. Page 11 production. J Lab Clin Med; $53: 807$.

[29] Kumar, R. (2010). Speciation of Candida isolates in significant count from urine samples.Ph. D. Thesis. University of Rajiv. Gandhi.

[30] Marcy, J. B. Douglas, K. A. (2005). Drug discovery from medicinal plants Life Sciences 78; 431 - 441

[31] Mahmoud, A. M., Hosnia, S. A. and Usama, T. M. (2014). Effect of Chinese Propolis Supplementation on Ross Broiler Chicks: Microbial Population in Fecal matter and Litter Journal of Advanced Veterinary Research Volume 4, Issue 2 (2014) 77-84

[32] Michael, J. L. and Burton, E. P. (2011). A Photographic Atlas for the Microbiology Laboratory 4th edition page 183.

[33] Monget, D., Duchesne, M. A. and Caniaux I. (1995). API Candida, a New IdentificationSystem for Yeasts. 7th E.C.C.M.I.D., Vienna, 26-30 March.

[34] Nahid, A., Aghdas, S. and Farhad, H. (2009). Bacteria Isolated from Post-Partum Infections.

Journal of Family and Reproductive Health. Vol.3 No.2

[35] Odds, F. C. and Davidson, A. (2000). "Room temperature" use of CHROMagar Candida. Diag Micriobiol Infect Dis; 38: 147-50.

[36] Omwenga, E. O., Ogol, C., Paul, K. M. and Paul, O. O. (2015). Ethnobotanical Identification and Anti-microbial Evaluation of Some Anti-Diarrhoreal Plants Used by the Samburu Community, Kenya. Malaysian Journal of Microbiology, Vol 8(2) pp. 68-74 68

[37] Payam, B., Elham, B., Hodjjat, Y., Roghiyyeh, A., Mahboubeh, A. C., and Djaafar, S. O. (2010). Urinary Tract Infections Associated with Candida albicans. Journal of ClinicalMedicine 5(4): 277-279.

[38] Pikal, J. M., Takayuki, D. and Patel S. (2010). Determination of End Point of Primary Drying in Freeze-Drying Process Control. AAPS PharmSciTech. 11(1): 7384.

[39] Prajapati, N. D., Purohit, S. S., Sharma and Tarun, K. (2010). A handbook of Medicinal plants. Acomplete source book. Agrobios publishers India. Page 140,150 .

[40] Telefo, P. B., Lienou, L. L., Yemele, M. D., Lemfack, M. C, Mouokeu C, Goka CS, Tagne, S. R. and Moundipa, F. P. (2011). Ethnopharmacological survey of plants used for the treatment of femaleinfertility in Baham, Cameroon. Journal of Ethnopharmacology136: 178-187.

[41] World Health Organization (2003a). Guidelines on good agricultural and collection practices for medicinal plants. Page 11

[42] World Health Organization Geneva (2003b). Basic laboratory procedures in clinical bacteriology 2nd edition page 79

[43] World Health Organization (2014). Traditional Medicine Strategy 2014-2023 Page 1, 2

[44] Yogayata, S. P and Vijay, D. W. (2012). Herbal medicines and nutritional supplements used in the treatment of glaucoma. Research Journal of Pharmaceutical, Biological and Chemical Sciences 3 (1): 331

\section{AUTHORS}

First Author - Jespher Nyaboke Onyango, BSC, Mount Kenya University and email address inyaboke@mku.ac.ke Second Author - Dr. Jackson Odhiambo Onyuka, Phd. Mount Kenya University, and email address jonyuka@mku.ac.ke 
Third Author - Jared Misonge Onyancha, MSc, Kenyatta University and email address onyancha.jared@mku.ac.ke Fourth Author - Patrick Ogembo Getonto, BSc, Mount Kenya University and email address ppgetonto059@gmail.com Correspondence Author - Author name, email address, alternate email address (if any), contact number. 